\title{
Development of Solar Biomass Drying System
}

\author{
Samson Mekbib Atnaw ${ }^{1, *}$, Che Ku Mohammad Faizal Bin Che Ku Yahya ${ }^{1}$, and Abduaziz \\ Jama Oumer $^{2}$ \\ ${ }^{1}$ Faculty of Engineering Technology, University Malaysia Pahang, Tun Razak Highway, 26300 \\ Kuantan, Pahang, MALAYSIA. \\ ${ }^{2}$ Faculty of Industrial Management, University Malaysia Pahang, Tun Razak Highway, 26300 \\ Kuantan, Pahang, MALAYSIA.
}

\begin{abstract}
The purpose of this paper focuses on the experimental pretreatment of biomass in agricultural site using solar energy as power source and contribution of common use and efficiency solar dryer system for consumer. The main purpose of this design for solar cabinet dryer is to dry biomass via direct and indirect heating. Direct heating is the simplest method to dry biomass by exposing the biomass under direct sunlight. The solar cabinet dryer traps solar heat to increase the temperature of the drying chamber. The biomass absorbs the heat and transforms the moisture content within the biomass into water vapour and then leaves the chamber via the exhaust air outlet. This problem however can be solved by adopting indirect solar drying system. High and controllable temperatures can be achieved as a fan is used to move the air through the solar collector. This project has successfully created a solar cabinet dryer that combines both direct and indirect solar drying systems and functions to dry biomass as well as crops effectively and efficiently with minimal maintenance. Hence, it is indeed a substitution for conventional dryers which are affordable to local farmers.
\end{abstract}

\section{Introduction}

Biomass is a biological material that is abstracted from living organism [1]. Malaysia is a country that has abundant source of biomass such as woods, sugar canes, organic matter and so on. In order to convert this biomass to electricity, it can undergo the gasification process in a gasification reactor [2]. For the gasification process it requires relatively low moisture input. In order to ensure an effective and complete combustion of biomass, it should undergo the pre-treatment process called drying or moisture removal [3]. Geographical location shows that Malaysia is located near the equator [4]. The scope of study for this work is to fabricate a solar cabinet dryer to dry biomass. The current study will cover the development of drying mechanism and heat transfer calculations and analysis in order to ensure efficient utilization of the solar heat inside the drying chamber. Equilibrium moisture content (EMC) for the biomass will be experimentally determined for

* Corresponding author: mekbibsams@um p.edu.my 
the specific biomass type to be studied. Therefore, the efficiency of this system can be estimated according to the EMC result.

\section{Background}

In many parts of the world there is a growing awareness that renewable energy have an important role to play in extending technology to the farmer in developing countries to increase their productivity [5]. Solar thermal technology is a technology that is rapidly gaining acceptance as an energy saving measure in agriculture application. It is preferred to other alternative sources of energy such as wind and tidal energy, because it is abundant, inexhaustible, and non-polluting. Solar air heaters are simple devices to heat air by utilizing solar energy and employed in many applications requiring low to moderate temperature below $80^{\circ} \mathrm{C}$, such as crop drying and space heating [6]. In addition to moisture removal of biomass, solar drying process plays an important role in the preservation of agricultural products. It is defined as a process of moisture removal due to simultaneous heat and mass transfer [7].

In order to improve traditional drying, solar dryers which have the potential of substantially reducing the above-mentioned disadvantages of open air drying have received considerable attention over the past 20 years. Though forced convection type of solar dryers could be effectively used, however they require electricity in order to operate the extraction fans. This may significantly increase the operation cost and also limit the use of dryer in rural areas where there is no elecricity. Even when electricity exists, the potential users of the dryers are unable to pay for it due to their very low income. Forced convection dryers are for this reason not going to be readily applicable on a wide scale in many developing countries [8-9]. Natural convection dryers circulate the drying air without the aid of a fan. They are therefore, the most applicable to the rural areas in developing countries.

Table 1. Merits and Demerits

\begin{tabular}{|l|l|l|}
\hline $\begin{array}{l}\text { The Applied Drying } \\
\text { Technique }\end{array}$ & Advantages & Disadvantages \\
\hline Open air drying & $\begin{array}{l}\text { No investment is required. } \\
\text { No fuel is required. }\end{array}$ & $\begin{array}{l}\text { The product is exposed to } \\
\text { risks such as dust, } \\
\text { animals, ants, rain, etc. }\end{array}$ \\
\hline Firewood/fuel drying & $\bullet \quad$ Faster than the open air type & $\begin{array}{l}\text { Cost of labor and building } \\
\text { the dryer box. }\end{array}$ \\
\hline Solar Drying & $\begin{array}{l}\text { Cheap, Environmentally } \\
\text { friendly and ease of } \\
\text { maintenance }\end{array}$ & $\begin{array}{l}\text { The difficult dryer } \\
\text { operation. }\end{array}$ \\
\hline
\end{tabular}

Shown in Table 1 is a summary of the merits and demerits of various drying methods. As shown in Table 1, there is a clear indication, that the solar drying technique is the most suitable for the small scale farmers to cover their needs, during the processing of cash crops. It is also suitable for drying the available fruits and vegetables.

\subsection{Solar Drying}

In solar drying the heat is created by the sun radiation. The heat could be circulated by a ventilator powered by PV array. The three first mentioned techniques can be replaced by the environmental friendly drying techniques. The Solar Dryer Technology and Utilization The description of the solar drying technologies will be limited to few types, which are very common and well known. Low Cost Solar Dryer: The low cost dryer has different varieties 
such as the cabinet solar dryer, the flat solar dryer, etc. The low cost dryer is the most suitable even for the small farmer, who have a very limited income. It will be possible for them to cover the investment cost. This is produced from locally available materials, and by local carpenter. Solar Dryer: This type developed for drying only food crops, cash crops and fruits. The dryer consists of: Sun collector panel for air heating, Drying chamber, Fan for the hot air circulation, Moisture and temperature sensor and PV-panel for powering the fan.

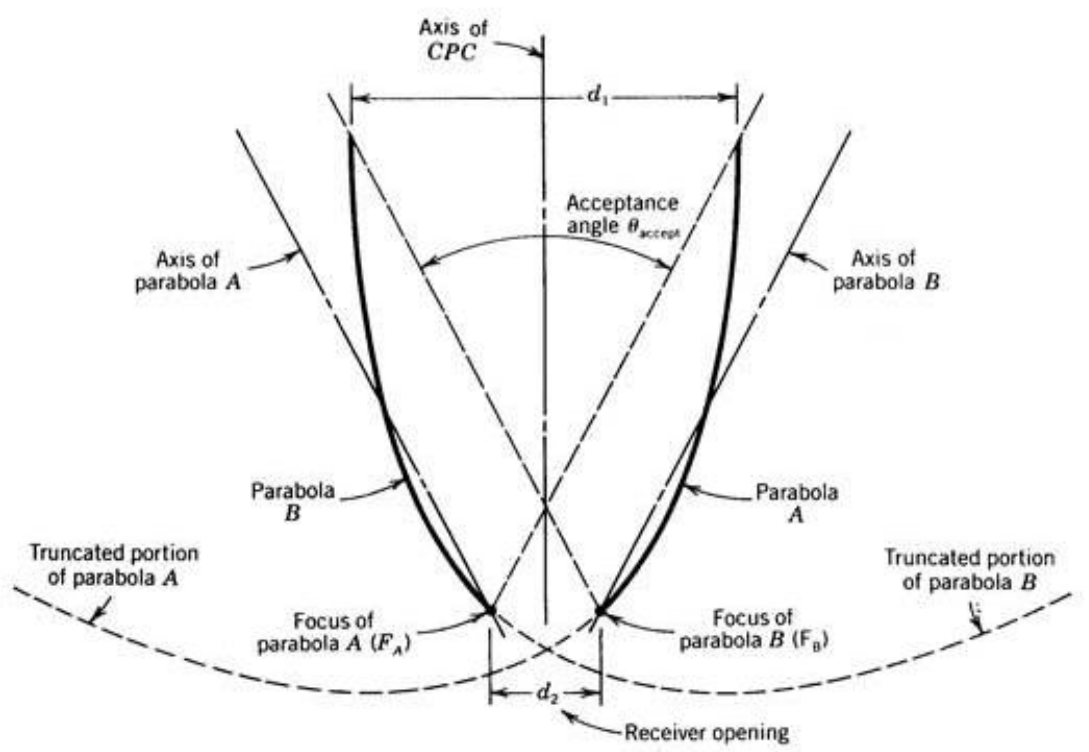

Fig. 1. Compound parabolic concentrator (CPC)

Initially, a mechanism that uses a compound parabolic concentrator (CPC) to heat the biomass was considered. CPC is comprised of two parabolic mirror segments with different focal points as indicated. It is capable of collecting direct sunlight as well as diffused sunlight without the need of a solar tracking system. However, it can attain a very high temperature up to $300{ }^{\circ} \mathrm{C}$ that makes it inappropriate for this drying process. The basic shape of the compound parabolic concentrator is illustrated in Fig 1.

The second type of design considered was a solar dryer based on the conventional solar dryer which uses direct drying or indirect drying. The solar dryer combines both drying methods so as to improve its efficiency. The design is illustrated in Fig 2. The biomass is laid out on trays, which sit behind a transparent glass. Sun beams heat up the incoming fresh air and force the hot air to move upwards. The hot air is then discharged via air outlet, taking the moisture from the biomass. 


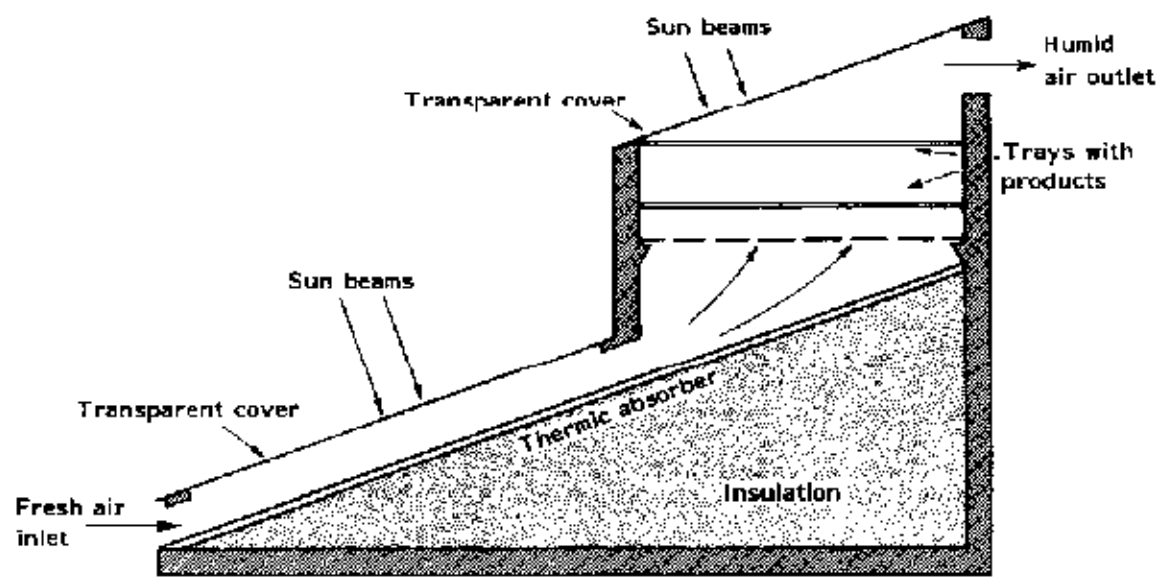

Fig. 2. Combined direct and indirect solar dryer

The moisture content of the biomass depends on the relative humidity and temperature of the air surrounding. Moisture content express the amount of water present in a moist sample. Moisture content can be expressed on wet basis or dry basis.

1. Moisture content(MC) on dry basis is the amount of water per unit mass of dry solids in the sample :

MC for dry basis $=\frac{\text { initial mass of sample }- \text { final mass of sample }}{\text { final mass of sample }} \times 100 \%$

2. Moisture comtent(MC) on wet basis is the amount of water per unit mass of moist or wet sample :

$\mathrm{MC}$ for wet basis $=\frac{\text { initial mass of sample }- \text { final mass of sample }}{\text { initial mass of sample }} \times 100 \%$

\section{Methodology}

The main purpose of this design for solar cabinet dryer is to dry biomass via direct and indirect heating. Direct heating is the simplest method to dry biomass by exposing the biomass under direct sunlight. The solar cabinet dryer traps solar heat to increase the temperature of the drying chamber.

Fig 3. shows the schematic representation of proposed solar drying system. The transparent glass is fixed at an inclination of $21^{\circ}$ to achieve a maximum absorption of solar radiation. The wall of the drying chamber ismade up of three different layers, i.e. fibreglass, wood and aluminium. Fibreglass is used as the outer layer because it makes a good heat insulator that prevents heat loss to the surrounding[10-12]. Wood isused as the middle layer due to its low cost. The inner layer is made of aluminium which has high resistivity against rust and corrosion[11]. As shown in Fig 3., the design of the drying chamber issimilar to a drawer cabinet that has two drawers. The drawer compartments are made up of aluminium and they are designed in such a way that they allow a maximum flow of hot air through the biomass. 


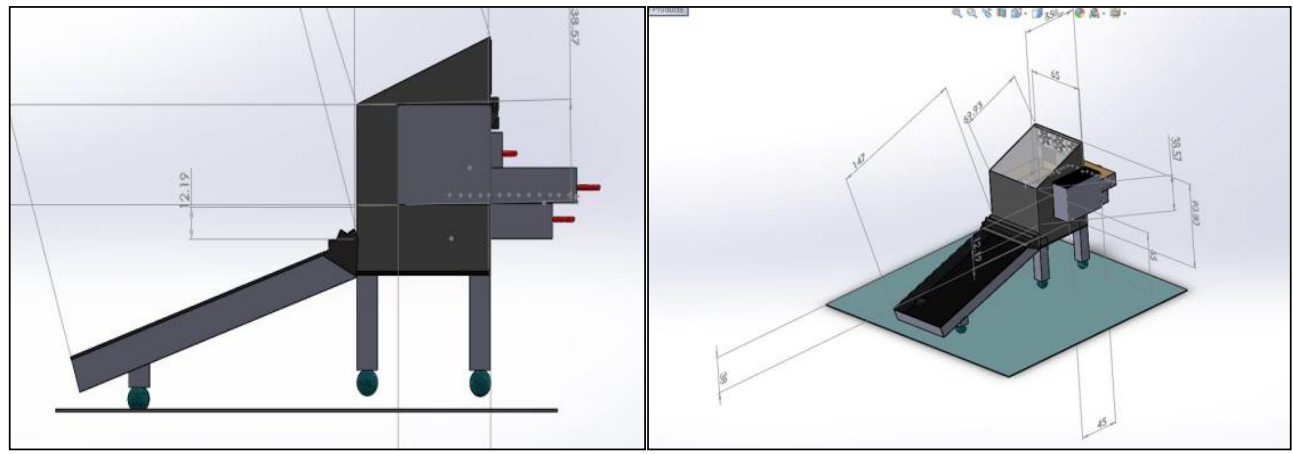

Fig. 3. Solar Cabinet Dryer

The whole ventilation system is driven by direct current (DC) generated from solar panels (PV).The air flow rate of the ventilation fan is 70 cubic feet per minutes (CFM). The temperature of position parts of the drying chamber is measured using type $\mathrm{K}$ thermocouple. The bottom is made up of aluminium and painted in black to increase the radiation absorptivity and emissivity. The top of the absorber is covered by a dark glass. The black surface will absorb the radiation and changes it into heat energy to heat up the incoming fresh air

This paper is conducted based on research and experiences into risk management its potential to prevent and eliminate risk and learning from performance team in industry which matched by an application in project refurbishment in Batam manufacturing Indonesia.

\section{Results and discussion}

After the course of study, the solar cabinet dryer is found to be more efficient on drying the coconut coir as compared to natural drying. In 3 days of continuous drying under the same climatic condition, a total of $31.46 \%$ moisture content was removed from sample 1,2 and 3 whereas only $21.99 \%$ of moisture content was removed from sample 4,5 and 6 . Moisture content (MC) of the coconut coir will be calculated by using dry basis method.

$\mathrm{MC}$ for dry basis $=\frac{\text { initial mass of sample }- \text { final mass of sample }}{\text { final mass of sample }} \times 100 \%$

Table 2. Drying Coconut Coir Experiment via Solar Cabinet Dryer

\begin{tabular}{|l|l|l|l|}
\hline Sample & Initial mass (g) & Final mass (g) & MC (\%) \\
\hline 1 & 23.4875 & 15.6826 & 33.23 \\
\hline 2 & 27.4722 & 19.5932 & 28.68 \\
\hline 3 & 19.1241 & 12.9164 & 32.46 \\
\hline Average & & 31.46 \\
\hline
\end{tabular}

After full drying at $107^{\circ} \mathrm{C}$ for 24 hours in the furnace, the moisture content of coconut coir is $0 \%$, implies that the sample 7, 8 and 9 do not containany water. The moisture loss of full drying process is $39.02 \%$. It indicates the total moisture content in coconut coir sample for experiment of solar cabinet dryer and natural drying process is $39.02 \%$. 
Table 3. Drying Coconut Coir Experiment via Natural Drying Process

\begin{tabular}{|l|l|l|l|}
\hline Sample & Initial mass (g) & Final mass (g) & MC (\%) \\
\hline 4 & 22.9496 & 17.7476 & 22.67 \\
\hline 5 & 22.1241 & 17.3972 & 21.37 \\
\hline 6 & 17.9478 & 14.0103 & 21.94 \\
\hline Average & 21.99 \\
\hline
\end{tabular}

The purpose of full drying experiment is to analyze the ability of sample to absorb moisture at room condition to achieve equilibrium moisture content (EMC). The sampleswere exposed in room condition for 3 days and the result was analyzed to determine the EMC of coconut coir.

Table 4. Drying Coconut Coir Experiment via Furnace for the Purpose of EMC

\begin{tabular}{|l|l|l|l|}
\hline Sample & Initial mass (g) & Full drying mass(g) & MC (\%) \\
\hline 7 & 4.4584 & 2.5721 & 42.31 \\
\hline 8 & 2.2811 & 1.8913 & 17.09 \\
\hline 9 & 4.6336 & 1.9613 & 57.67 \\
\hline Average & & 39.02 \\
\hline Sample & Full drying mass(g) & Final mass(g) & EMC (\%) \\
\hline 7 & 2.5721 & 2.9119 & 11.67 \\
\hline 8 & 1.8913 & 2.2351 & 15.38 \\
\hline 9 & 1.9613 & 2.2510 & 12.87 \\
\hline Average & & 13.31 \\
\hline
\end{tabular}

\section{Conclusion}

Direct solar drying allows direct absorption of solar radiation by the biomass which is the most effective way of converting solar radiation into useful heat for drying. The final dried quality of biomass is also enhanced by direct exposure to solar radiation. However, because the biomass absorbs solar radiation directly, its temperature is difficult to control. This problem however can be solved by adopting indirect solar drying system. High and controllable temperatures can be achieved as a fan is used to move the air through the solar collector. This project has successfully created a solar cabinet dryer that combines both direct and indirect solar drying systems and functions to dry biomass as well as crops effectively and efficiently with minimal maintenance. Hence, it is indeed a substitution for conventional dryers which are affordable to local farmers.

The authors would like to acknowledge the support from University Malaysia Pahang and Malaysian Ministry of Higher Education FRGS grant (RDU140109).

\section{References}

1. P.Basu, Biomass Gasification, Pyrolysis and Torrefaction (2 ${ }^{\text {nd }}$ Edition) Practical Design and Theory, (Academic Press, 2013)

2. R.L. Earle, Unit operations in food processing, (Oxford Pergamon Press, 2003)

3. The Free Encyclopedia.Geography of Malaysia (Wikipedia, 2015) 
4. J.A. Waewsak, Int. J. Sci. Technol., 11, 14 (2006)

5. I. Kurtbas, E. Turgut, Int. J. Sci. Technol., 1, 75 (2006)

6. C. Ertekin, O. Yaldiz, J. Food Eng., 63, 349 (2004)

7. Y.H. Hui, Food Drying Science and Technology: Microbiology, Chemistry, Applications, (DEStech Publications 2008)

8. A. Gatea, Journal of Agricultural Biotechnology and Sustainable Development, 2, 39 (2010)

9. S.M. Atnaw, S.C. Kueh, S.A. Sulaiman, Sci. World J., 8 (2014)

10. Thermal Insulation Association of South Africa Thermal insulation-the invisible energy saver: The Guide to Energy Efficient Thermal Insulation Buildings, (Midrand, AAAMSA administered 2010)

11. S.A. Sulaiman, M.R.T. Ahmad, S.M. Atnaw, AIP Proceedings, 981 (2012)

12. S.M. Atnaw, S.A. Sulaiman, S. Yusup, Scientific World J., (2014) 